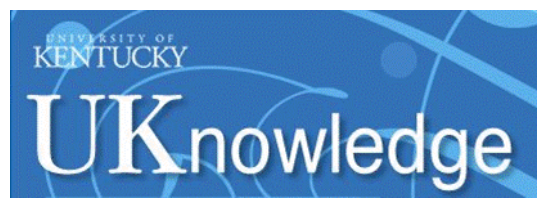

University of Kentucky

UKnowledge

\title{
The Effects of Depletion and Brain Stimulation on Motivation
}

\author{
Sarah Beth Bell \\ University of Kentucky, sarah.beth.bell@uky.edu \\ Digital Object Identifier: https://doi.org/10.13023/ETD.2017.154
}

Right click to open a feedback form in a new tab to let us know how this document benefits you.

\section{Recommended Citation}

Bell, Sarah Beth, "The Effects of Depletion and Brain Stimulation on Motivation" (2017). Theses and Dissertations--Psychology. 113.

https://uknowledge.uky.edu/psychology_etds/113

This Master's Thesis is brought to you for free and open access by the Psychology at UKnowledge. It has been accepted for inclusion in Theses and Dissertations--Psychology by an authorized administrator of UKnowledge. For more information, please contact UKnowledge@lsv.uky.edu. 


\section{STUDENT AGREEMENT:}

I represent that my thesis or dissertation and abstract are my original work. Proper attribution has been given to all outside sources. I understand that I am solely responsible for obtaining any needed copyright permissions. I have obtained needed written permission statement(s) from the owner(s) of each third-party copyrighted matter to be included in my work, allowing electronic distribution (if such use is not permitted by the fair use doctrine) which will be submitted to UKnowledge as Additional File.

I hereby grant to The University of Kentucky and its agents the irrevocable, non-exclusive, and royalty-free license to archive and make accessible my work in whole or in part in all forms of media, now or hereafter known. I agree that the document mentioned above may be made available immediately for worldwide access unless an embargo applies.

I retain all other ownership rights to the copyright of my work. I also retain the right to use in future works (such as articles or books) all or part of my work. I understand that I am free to register the copyright to my work.

\section{REVIEW, APPROVAL AND ACCEPTANCE}

The document mentioned above has been reviewed and accepted by the student's advisor, on behalf of the advisory committee, and by the Director of Graduate Studies (DGS), on behalf of the program; we verify that this is the final, approved version of the student's thesis including all changes required by the advisory committee. The undersigned agree to abide by the statements above.

Sarah Beth Bell, Student

Dr. C. Nathan DeWall, Major Professor

Dr. Mark Fillmore, Director of Graduate Studies 


\section{THESIS}

A thesis submitted in partial fulfillment of the Requirements for the degree of Master of Sciences in the College of Arts and Sciences at the University of Kentucky

By

Sarah Beth Bell

Lexington, Kentucky

Director: Dr. C. Nathan DeWall, Professor of Psychology

Lexington, Kentucky

2017

Copyright (C) Sarah Beth Bell 2017 


\section{ABSTRACT OF THESIS}

\section{THE EFFECTS OF DEPLETION AND BRAIN STIMULATION ON MOTIVATION}

Mental fatigue decreases motivation. I tested whether applying electricity to a self-control region of the brain would replenish some of the motivation normally lost during mental fatigue. 224 people participated in this study. Each person received real or placebo brain stimulation while undergoing activities that increased mental fatigue. The dependent variable was a task where participants had to perform work by clicking a computer mouse repeatedly. Before performing this task, participants indicated how hard they were planning to work on this motivation task. Participants who received real brain stimulation were able to perform more work, but only if they also indicated they planned to work hard on the task.

KEYWORDS: brain stimulation, depletion, self-control, tDCS, motivation

Sarah Beth Bell

April 17, 2017 


\section{THE EFFECTS OF DEPLETION AND BRAIN STIMULATION ON MOTIVATION}

By

Sarah Beth Bell

Dr. C. Nathan DeWall Director of Thesis

Dr. Mark Fillmore

Director of Graduate Studies

April 17, 2017 
To my cohort and closest friends:

Brian Enjaian, Andrew Nelson, Ilyssa Salomon, and Taylor Elsey 


\section{TABLE OF CONTENTS}

List of Figures............................................................

Chapter One: Introduction......................................................

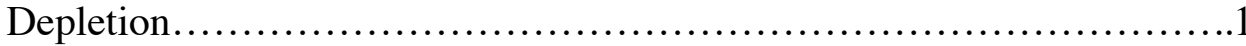

The Progressive Ratio Task .......................................6

Brain Stimulation................................................... 8

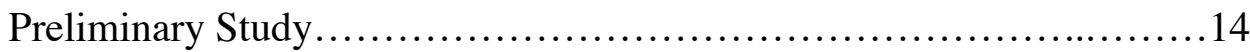

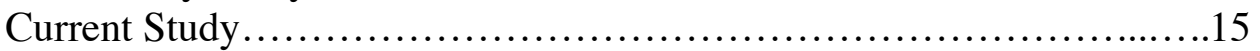

Chapter Two:

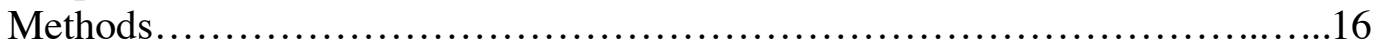

Participants......................................................

Materials and Manipulations........................................17

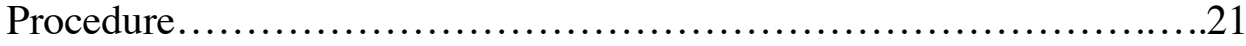

Planned Analyses....................................................

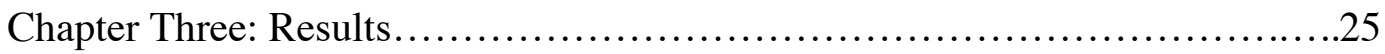

Chapter Four:

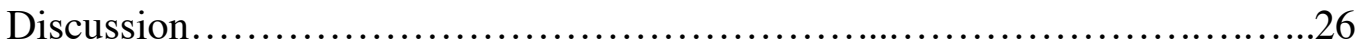

Different Results Than Expected...................................28

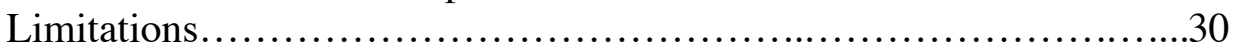

Future Directions...................................................

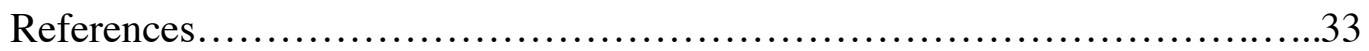

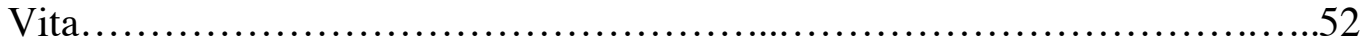




\section{LIST OF FIGURES}

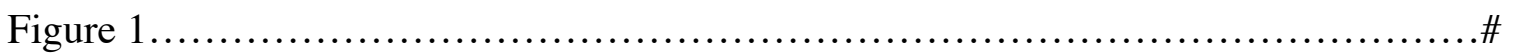

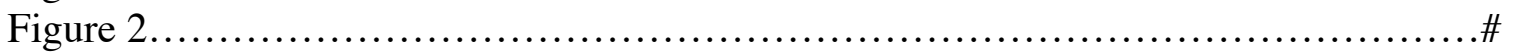

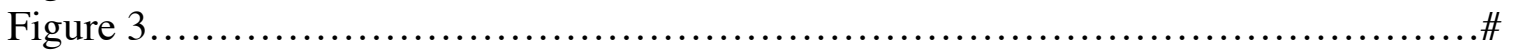




\section{Chapter 1: Introduction}

Imagine a device that could enhance your normal brain activity. It may sound futuristic, but an electronic cognitive enhancement tool has recently been developed. Transcranial direct current stimulation (tDCS) adds tiny amounts of electricity to a targeted area of the brain's cortex, making the neurons in the targeted area more likely to fire (Bennabi et al., 2014; Jacobson, Kozlowsky, \& Lavidor, 2012).

tDCS has already shown success in increasing working memory (Martin et al., 2013; Sandrini et al., 2012), mathematical learning (Luculano \& Kadosh, 2013), and error detection (Harty et al., 2014). It also may protect people from depletion, the process by which mental exertion decreases self-control. In my study, participants will undergo depletion, and I will see if tDCS protects them the behavioral effects of mental fatigue.

First, I will expand on depletion, including multiple theoretical models as well as the relationship between depletion and reward sensitivity. Next, I will describe a reward sensitivity task, called the progressive ratio task, which serves as the primary dependent variable in this study. After that, I will discuss how tDCS works as well as previous tDCS research in this area. Next, I will describe a preliminary behavioral study in my laboratory that serves as a pilot for the current study. Finally, I will specifically outline the current study and my hypotheses.

\section{Depletion}

Depletion occurs when willpower runs out. In the strength model, willpower is drawn from a finite reserve, and tasking mental exercises can deplete this resource (Baumeister, Vohs, \& Tice, 2007; MacKenzie \& Baumeister, 2015; Vohs et al., 2014). This lack of willpower leads to low self-control, as the depleted person is too 
fatigued to function at maximum capacity (see Haggar et al., 2010 for a meta-analysis on depletion). In the strength model, self-control can be thought of as a muscle. It can become tired, but it can also get stronger with practice (Baumeister \& Vohs, 2016; Hagger \& Chatzisarantis, 2013).

There are two major alternative theories to the strength model. The first is the nonlimited resource theory (Job et al., 2015). This theory posits that whether or not selfcontrol is diminished after depletion depends on whether people believe their willpower resources are limited or infinite (Job, Dweck, \& Walton, 2010; Miller et al., 2012; Walton, Bernecker, \& Dweck, 2015). However, even researchers who guide their work by this theory find some limits to willpower in their work. For example, willpower affects behavior after moderate depletion but not after severe depletion (Job, Dweck, \& Vohs, 2010). Despite evidence supporting strength model, I will test whether the nonlimited resource theory better supports my findings. Participants will complete a willpower scale that indicates their beliefs about whether willpower is limited or nonlimited. If these beliefs affect the results, contrary to my hypotheses, I would be providing evidence for the nonlimited resource theory.

The other major alternative model to the strength model is called the process model, and also known as the shifting priorities model (Inzlicht \& Schmeichel, 2012). In this model, self-control is thought to wane after depletion not because people are unable to control themselves but because people are unwilling to control themselves (Inzlicht \& Scmeichel, 2012). After depletion, people do not want to taking care of their responsibilities and more inclined to relax (Inzlicht, Schmeichel, \& Macrae, 2014). However, the theory is that people could force themselves to exercise self-control if they 
want to, and the reason they often do not after depletion is that they just do not want to. Motivation, rather than ability, is key.

Strength model theorists would disagree with the idea that motivation can overcome all depletion effects. This is because depletion is not only a loss of motivation but also a physiological loss of energy stores including glucose (Baumeister \& Vohs, 2007; Gailliot et al., 2007; Hagger \& Chatzisarantis, 2013). There is debate on exactly how glucose and other physiological factors change after depletion, with some findings failing to replicate (Chatzisarantis \& Hagger, 2015; Lange et al., 2014; Vadillo, Gold, \& Osman, 2016). Despite this, much evidence still exists in favor of some physiological limitations related to depletion (see Baumeister \& Vohs, 2016, for discussion). Strength theorists have updated the strength model to include a central governing system. That system seeks to conserve glucose but also is not fully informed of the body's glucose stores; allocation of energy sources is key (Baumeister \& Vohs, 2016; Evans, Boggero, \& Segerstrom, 2015). While increasing findings will help to fine-tune how physiology is related to depletion, glucose findings that have replicated suggest that motivation alone cannot overcome depletion. However, in my study, I will test whether the process model better describes our results. I will measure how motivated people are to work after depletion. If motivation completely overrides depletion, I will be providing evidence for the process model despite my hypotheses.

Another point of debate in the depletion literature is the multi-laboratory preregistered depletion replication project, also referred to as the RRR. In this project, many laboratories conducted replications of a specific depletion paradigm. The results of this 
project suggested that depletion had small to negligible effects (Hagger \& Charzisarantis, 2015), resulting in a hot debate in the field.

When taking a closer look at the RRR, we can examine possible reasons the depletion effect failed to replicate in this project (see Baumeister \& Vohs, 2016 for discussion). First, the task that was used in the study was administered in an alternate form that was less likely to induce depletion. The task used was called the crossing out e's task (as described in Sripada et al., 2014). The task consists of forming a habit and then breaking that habit. The habit is crossing out the letter e in a text, and the habit is broken by switching to a new rule in the second phase of the task where only certain e's are crossed out according to complex rules. In the RRR, only the second phase of the task was used, and thus a habit was never formed. Therefore, this task that has proven to be successful at depleting people (Baumeister, 1998; DeWall, 2008; Tice et al., 2007) was not administered in its original form, which may be a large driving factor of why it was not successful at depleting people in the RRR.

Another, albeit less glaring, criticism of the RRR is the external validity of the task used. The RRR insisted on using a computerized paradigm that could be performed regardless of language. People simply pressed a button to indicate whether each e should be crossed out or not. This kind of depletion exercise is stripped of context as compared to the depletion that happens in the real world (Baumeister \& Vohs, 2016). Moving away from cognitive tasks and towards behavioral and neural tasks may help us better understand depletion (Inzlicht, Gervais, \& Berkman, 2016). With that in mind, the present tDCS study does move in this direction, combining classic depletion tasks with the effects of brain stimulation. 
Depletion increases reward sensitivity. After depletion, less cognitive resources are available to exercise self-control, and we are more likely to succumb to temptation (Baumeister \& Vohs, 2016; Hofmann, Rauch \& Gawronski, 2007). People have an increase in approach motivation after depletion (Baumeister \& Vohs, 2016; Schmeichel, Crowell, \& Harmon-Jones, in press).

One study found that after exercising self-control, people were more likely to pay attention to reward-related stimuli as opposed to neutral stimuli (Schmeichel, HarmonJones, \& Harmon-Jones, 2010). Another found that people are likely to drink more alcohol following depletion (Muraven, Collins, \& Neinhaus, 2002). People are more likely to waste their money on impulsive purchases after depletion (Vohs \& Faber, 2007). After depletion, people are also more likely to overeat (Kahan et al., 2003; Vohs \& Heatherton, 2000). fMRI evidence shows that depleted dieters have increased activity in reward areas of the brain as compared to non-depleted dieters when they look at junk food (Wagner et al., 2013). After exerting self-control, people perform less accurately on the Stroop task, but a monetary incentive can reverse this effect (Luenti, in press). All of these findings come together to make a strong case for depletion increasing reward sensitivity in a variety of domains.

In my study, participants will undergo 15 minutes of depletion tasks. During the depletion tasks, some participants will receive brain stimulation to a region related to self-control, which I expect to diminish the effects of depletion. Other participants will only receive sham brain stimulation. The stimulation will continue throughout the entirety of the depletion exercises, and will be removed after depletion is over. After removing the brain stimulation device, I will measure reward sensitivity in my 
participants. A task called the progressive ratio task will be used to measure reward sensitivity.

\section{The progressive ratio task}

The progressive ratio (PR) task requires people to press a button a certain number of times to obtain a reward like a point or another reinforcer. Performance on the PR task is indicative of reward sensitivity (Der-Avakian \& Markout, 2012; Hodos, 1961; Miras et

al., 2012). The task requires a base number of responses to obtain the first reinforcer and an increasing number of responses to obtain each subsequent reinforcer. My study will use the PR task as a measure of reward sensitivity.

The PR task has been widely used in humans and non-human animals to assess motivation for rewards (Baron \& Derenne, 2000; Chelonis, Gravelin, \& Paule, 2011; Richardson \& Roberts, 1996). In humans, a common use of the task is to determine how much work people are willing to perform for an addictive drug (Depoortere et al., 1993; Rush et al., 2001; Rusted et al., 1998). It can be used with any kind of reinforcer, including food and money (Chelonis et al., 2011; Paule et al., 1990).

The PR task is a delay-discounting task (Epstein et al., 2010; Winstanley et al., 2003). The more button presses required to obtain a reward, the less likely people are willing to perform them (Rowlett, 2000; Stoops, 2008). Imagine if you had to press a button more and more times to get a reward. At a certain point, your responses would slow or stop.

In the PR task, the point at which the person decides the amount of button presses is too high for the reinforcer and stops responding is known as the breakpoint (Czachowski \& Samson, 1999; Miras, Jackson, \& Jackson, 2012). In my study, I do not 
expect people to reach a breakpoint in the task, as the task is timed to last only five minutes. However, I do expect performance to slow down, resulting in fewer button presses. In a preliminary study, I used the PR task after depletion, and almost no participants reached breakpoint during the five minute task. I plan to measure reward sensitivity on the task by number of button presses rather than by breakpoint in the current study.

Impulsivity is highly correlated with reward sensitivity (Buckholtz et al., 2010; Crews and Boettiger, 2009; Kreek et al., 2005). Therefore, it is not surprising that impulsivity predicts more button presses on the PR task. This phenomenon was first studied in animals (Anket et al., 2009; Diergaarde et al., 2008; Schippers et al., 2012). In the 1960 s, researchers were interested in creating animal models of hypertension to study cardiovascular disease. They created a breed of rat that develops very high blood pressure in adulthood (Okamoto, 1963). These rats are called spontaneously hypertensive rats (SHRs). It became apparent to researchers that these rats were incidentally quite hyperactive (Knardahl \& Sagvolden, 1979; McCarty \& Kopin, 1979; Myers, Musty, \& Hendley, 1982). They are now used in animal models of ADHD, a disorder characterized by impulsive behavior (Miller et al., 2014; Sterly, Fleur, \& Russell, 2013; Yang et al., 2015).

While the PR task is used in human-animal translational research on impulsivity, it is also now used in humans as well to see how much people will work to get a reward. Specifically, this task is often used in the addiction literature, and participants can work for drugs. For example, one study found that smokers with ADHD would perform more work for puffs of cigarettes than their less impulsive non-ADHD counterparts (Kollins et 
al., 2013). Another found that more impulsive people would perform more work on a PR task to obtain intravenous alcohol (Zimmerman et al., 2013). The task has even been used to study the addictive nature of food. Nonobese adults were able to earn food through points on a progressive ratio task. Impulsive people not only pressed the button more in the PR task but also gained more weight over time (Carr et al., 2013).

These PR studies have demonstrated that impulsive people will perform more work to get rewards. A less impulsive person might have the ability to delay getting the reward until a better time or resist it altogether, but the impulsive person sees it and wants it now. However, getting the reward may take a little work. In the real world, they might have to stop off and buy it. In the case of obtaining an especially pleasurable reward like a drug, much planning and coordination might go into the process of arranging to get it. However, the impulsive person will be more likely to do the work. The fleeting impulse sets off a chain of reward seeking behavior.

In my study, I will use the PR task to understand how depletion affects reward sensitivity. Participants will also complete a measure of impulsivity. These results will be used to see if impulsivity moderates the relationship between depletion and reward sensitivity. In addition, tDCS brain stimulation will be performed during the depletion exercises in the present study.

\section{tDCS}

Scientists have long sought to understand the relationship between brain and behavior (Knudsen, 2004; Rosenzweig \& Bennett, 1996). Neurological devices and equipment such as EEG and fMRI have helped researchers learn more about how a variety of brain structures affect cognition and behavior (Cabeza \& Nyberg, 2000; 
Klimesch, 1999). Transcranial direct current stimulation (tDCS), a relatively novel medical device, can increase the flow of electricity into chosen regions of the brain (Filmer, Dux, \& Mattingley, 2014). By using a very mild electrical current, neurons can become more or less likely to fire in the targeted brain region (Bennabi et al., 2014; Jacobson, Koslowsky, \& Lavidor, 2012). tDCS works by using the electricity to depolarize neurons in the targeted area. This depolarization makes it more likely that the neuron will fire, but it does not actually make it fire due to the mildness of the stimulation (Filmer, Dux, \& Mattingley, 2014).

There are two types of tDCS stimulation available, anodal and cathodal. Anodal stimulation, discussed in the previous paragraph, makes neurons in the targeted area more likely to fire by depolarizing them. Likewise, cathodal stimulation makes neurons in the targeted area less likely to fire by hyperpolarizing these neurons (Filmer, Dux, \& Mattingley, 2014). The present study will only use anodal stimulation, for two reasons. First, I wish to see if tDCS can counteract the effects of depletion. In theory, cathodal stimulation to the rVLPFC would magnify the effects of depletion, which has less practical application. Second, the effects of cathodal stimulation are more variable than the effects of anodal stimulation. For example, a meta-analysis has found cathodal stimulation to be much more effective on motor than cognitive realms, only effective in cognitive realms in a minority of studies (Jacobson, Koslowsky, \& Lavidor, 2012).

The control for anodal stimulation in this study is sham stimulation. Sham stimulation involves ramping up tDCS for 30 seconds, stimulating for 30 seconds, and ramping the device back down for 30 seconds. After a total of 90 seconds, the device is turned off. Participants experience the physiological affects of tDCS turning on, such as 
mild skin tingling, making the stimulation seem real. However, it does not last long enough to affect brain activity in any meaningful way (Brunpmo et al., 2012; Filmer, Dux, \& Mattingley, 2014).

A full discussion of tDCS must note current controversy about the effectiveness of the method. Recently, tDCS was applied to cadavers, and it was discovered that only $10 \%$ of the current applied was getting through the skin and skull to the brain (Underwood, 2016). The rest of the electricity was being spread through the skin only and not getting through to the brain. Because so much electricity was being lost, it was claimed that at least $5 \mathrm{~mA}$ of stimulation were needed to produce a meaningful current, while the FDA has only approved a dose of up to $2 \mathrm{~mA}$ (Underwood, 2016).

Despite this finding, there are a plethora of successful tDCS studies, many of which are described in this paper. This begs the question of how tDCS works if hardly any of the electricity is actually getting to the brain. We are still beginning to understand exactly how tDCS works. One component of how electricity affects the body relates to changes in sodium and calcium channels in the brain. Surprising, there can be surges in these channels without a change in the local field electrical potential (Monai et al., 2016). Therefore, tDCS may not be obviously changing an electrical potential in the brain but rather operating via this smaller, more specific level. These channels also closely related to glial cell signaling, while previous studies have focused on neurons (Fertonani \& Miniussi, 2016). Whether electricity, sodium/calcium channels, glial cell communication, or some combination of these three or other undiscovered factors affect how tDCS works, the literature contains thousands of studies showing it to be effective (see Boggio et al., 2016 for review). 
tDCS is beginning to gain popularity as a tool to use in social neuroscience research. To understand the growing history of tDCS in social psychology, it is important to first look at the device's predecessor. Transcranial magnetic stimulation (TMS) uses a magnetic field generator called a coil to produce small electrical currents in the brain via electromagnetic induction (Ben-Shakar et al., 1997). TMS began to be used in social psychology in 1996, and its popularity increased over the years (Boggio et al., 2016). Evidence began to show how TMS could powerfully affect social cognition in a variety of realms (Boggio et al., 2016). However, it unfortunately caused seizures in some people. tDCS is much safer than TMS and does not cause seizures (Bruoni et al., 2011; Filmer, Dux, \& Mattingly, 2014). In addition, tDCS is easier to use and creates a more realistic placebo condition (Boggio et al., 2016).

By the time tDCS gained popularity, TMS had already laid the groundwork for brain stimulation as a helpful tool in social psychology. tDCS built upon this groundwork by studying the effect of brain stimulation in a variety of areas. tDCS has been found to be effective in reducing social pain (Boggio, Zaghi, \& Fregni, 2009; Kelley, Hortensius, and Harmon-Jones, 2013). It has successfully increased emotion detection in facial stimuli (Boggio, Rocha, da Silva, \& Fregni, 2008; Ferrucci et al., 2012). It has also been used as a modulation tool in a variety of decision-making paradigms (Civai et al., 2012; Ruff, Ugazio, \& Fehr, 2013; Spitzer et al., 2007).

According to the strength model, depletion results in diminished self-control. Therefore, in my study, I will use tDCS to target a self-control area of the brain called the right ventrolateral prefrontal cortex (rVLPFC). The rVLPFC has a rich history in social psychology. It has been studied via fMRI largely for its role in reducing social pain 
(Lieberman \& Eisenberger, 2008; Masten et al., 2009; Yanagisawa et al., 2011).

However, more recent research has found evidence for its important role in selfregulation (Cohen et al., 2013; Riva et al., 2014; Welborn et al., 2015).

The balance model lays a theoretical basis for how parts of the prefrontal cortex, which include the rVLPFC, relate to self-control (Heatherson and Wagner, 2011). According to this theory, one role of the prefrontal cortex is to control urges for rewards that arise from more central parts of the brain including the nucleus accumbens (NAcc). When the prefrontal cortex is working well, it works in a circuit with reward centers deeper in the brain. However, when the prefrontal cortex is not performing optimally, such as after heavy depletion, this circuit is partially broken, resulting in reward areas of the brain essentially overriding the prefrontal cortex, tipping the balance between the two parts of the brain in favor of the reward areas (Heatherson and Wagner, 2011). Specifically, the rVLPFC has been called the brain's braking system because of its key role in this circuit (Lieberman, 2009).

Other researchers are already using tDCS in an attempt to increase self-control following depletion. When applied to the prefrontal cortex, tDCS can reduce risk-taking (Fecteau et al., 2007; Hare, Camerer, \& Rangel, 2009), aggression (Dambacher et al., 2015; Riva et al., 2014), and excessive food consumption (Kekic et al., 2014; Lapenta et al., 2014). One study to date specifically studies the relationship between tDCS, selfcontrol, and depletion (Loftus et al., 2015), and is likely the closest existing study to my study. Participants performed the Stroop task, and then received anodal or sham stimulation. Afterwards, they performed the Stroop task again. After tDCS, participants who received anodal stimulation were faster at the Stroop than the people who received 
sham stimulation. However, accuracy differences between the two groups did not emerge. Despite this, people who received anodal stimulation were more accurate after they received the stimulation than they were in the task that was administered before the stimulation began, while this difference did not emerge for people in the sham stimulation group (Loftus et al., 2015). This study provides evidence that tDCS can reduce the effects of depletion, which is an important basis for the present study.

tDCS researchers seeking to understand self-control have targeted multiple areas of the PFC. The Loftus et al. (2015) study described in the previous paragraph targeted the DLPFC, and others have done the same (see Boggie et al., 2016 for review). However, I choose to target the rVLPFC due to research that has strongly linked it specifically to self-control (Cohen et al., 2013; Lieberman, 2009; Welborn et al., 2015)

In summary, one way depletion manifests itself is with diminished self-control (Baumeister \& Vohs, 2016), which results in increased reward sensitivity (Schmeichel, Harmon-Jones, \& Harmon-Jones, 2010; Vohs \& Faber, 2007; Wagner et al., 2013). I will disrupt the depletion process in this study by stimulating the rVLPFC, which I hypothesize will lessen depletion, as this self-control area of the brain will be able to work harder with the stimulation. Half of the participants will receive anodal stimulation, while the other half will merely receive sham stimulation. After stimulation, I will then use PR task to measure reward sensitivity, a behavioral byproduct of depletion. If the rVLPFC is working harder when people are receiving stimulation, then the link between reward areas deep in the brain such as the NAcc and inhibitory areas such as the rVLPFC should remain strong despite depletion. While normally depletion can lessen the connection between the PFC and reward centers of the brain (Heatherson \& Wagner, 
2011), I do not expect this to happen with the aid of tDCS. If people who receive anodal stimulation show less reward sensitivity than people who merely receive the sham stimulation, then my brain stimulation paradigm will provide important evidence of the role of the rVLPFC in the self-regulatory circuit.

\section{Preliminary study}

I conducted a previous depletion study that I will build on in the current study. 278 people from the University of Kentucky subject pool participated in this study (64\% female; $\mathrm{M}_{\mathrm{age}}=19.22, \mathrm{SD}=1.02 ; 78 \%$ White). In the previous study, participants first completed the Monetary Choice Questionnaire (MCQ) as a measure of impulsivity. This delay-discounting measures asks people a series of questions regarding whether they would like a smaller amount of money right now or a large amount of money after a variable number of days. Low scores on the MCQ indicate more impulsivity, and high scores indicate less impulsivity.

Next, participants underwent either depletion or control exercises. Two different depletion exercises were used in this study, and each participant received only one of the two types of depletion. Some participants performed the Stroop task, while others performed the Attention Control task.

In the Stroop task (Stroop, 1936), people saw words for colors printed in different font colors. In the control condition, the words and the font colors were the same, i.e. the word blue printed in a blue font. In the experimental condition, the words and the font colors were different, i.e. the word blue printed in a red font. The participants had to identify the font color of the word. 
In the Attention Control task (described in Gailliot et al., 2007), participants watched a silent video with distracting words that popped up in the corner of the screen. In the control condition, participants were merely instructed to watch the video. In the depletion condition, participants were told they must consciously ignore the distracting words on the corner of the screen, immediately redirecting their attention to the video whenever they saw one of these words.

We used two different depletion tasks to see if differences in behavior emerged after the tasks. However, results on the dependent variable were statistically indistinguishable across the two tasks, so they were collapsed in analyses.

After participants completed depletion or control exercises depending on condition, reward sensitivity was measured. I used a progressive ratio (PR) task to measure reward sensitivity in this study. The reward participants received in this study was points on the PR task.

I analyzed the effects of depletion and impulsivity as measured by MCQ score on reward sensitivity. Participants who were less impulsive performed similarly on the reward sensitivity task whether they were depleted or not. However, participants who were both depleted and high in impulsivity showed elevated reward sensitivity on the PR task (see Figure 1).

\section{Current study}

My study examined the mechanisms behind depletion using a novel paradigm. The present study added tDCS to the same paradigm as the previous study to manipulate a neural mechanism thought to be behind depletion. First, participants completed the Monetary Choice Questionnaire as a measure of impulsivity, as used in the previous 
study. Next, the Theories of Willpower Scale was administered. After that, participants underwent depletion. However, in this study, participants received tDCS stimulation to the rVLPFC, a self-control area of the brain, during depletion. Half of participants received real, anodal stimulation thought to make neurons in this area more likely to fire, while the other half only received sham stimulation. Next, tDCS was turned off. Participants completed a two-item measure relating to the process model of depletion. Finally, participants completed the PR task as a measure of reward sensitivity.

First, I hypothesized that the results of the previous study would be replicated. I expected impulsive people to demonstrate more reward sensitivity on the PR task when they received sham stimulation, mimicking the depletion condition in the preliminary study. I also hypothesized that tDCS would diminish the effects of depletion. I expected less impulsive people would perform similarly on the reward sensitivity task regardless tDCS stimulation. However, for more impulsive people, I expected tDCS to counteract the increased reward sensitivity seen after depletion, bringing their performance on the reward sensitivity task closer to that of their less impulsive counterparts. While fMRI studies have looked at the brain during depletion, I augmented activity in the rVLPFC using tDCS. These results would provide a new kind of evidence that self-control exhaustion in the rVLPFC is a true driving factor behind the phenomenon of depletion.

\section{Method}

\section{Participants}

224 participants were drawn from the University of Kentucky subject pool $(77.5 \%$ female, $75.8 \%$ White, mean age=18.9). The number of participants was determined using a power analysis described in the expected results section of this paper. 
Participants were only eligible if they have completed the pre-screen measure through the subject pool website. Only participants who qualified for the study after the prescreen measure were able to enroll.

Exclusion criteria for the study are thorough to ensure safety of the participants. Participants could not be under the age of 18 . They could not have metal in the head (except in the mouth), including metal fragments from occupational exposure, and surgical clips near the brain. They could not have cardiac or neural pacemakers. They could not be pregnant or suspect they might be pregnant. They could not have a history of severe alcohol or drug abuse. They could not be left-handed or ambidextrous. They could not have ever been diagnosed with a neurological disorder. They must not have been currently taking or have previously taken any anti-epileptic medications. They could not have ever been diagnosed with a psychiatric disorder. They could not have ever suffered a closed head injury or concussion. They could not be on any medications that affect the central nervous system, defined as a broad spectrum of psychiatric and pain management drug classes including but not limited to opioids, barbiturates, benzodiazepines, stimulants, SSRIs, and general anesthetics. They could not have ever been diagnosed with a learning disability. Finally, they could not be under the influence

of alcohol or other recreational drugs while completing the study, as measured by asking them if they are under the influence as well as visual inspection.

\section{Measures and Manipulations}

Theories of Willpower Scale

The Theories of Willpower Scale (described in Job, Dweck. \& Walton, 2010) assesses the extent to which people believe their willpower is limited or nonlimited. It 
includes items such as "After a strenuous mental activity, you energy is depleted and you must rest to get it refueled again" and "Your mental stamina fuels itself; even after strenuous mental exertion, you can continue doing more of it". The first item relates to the strength model, and the second item relates to nonlimited resource theory.

The purpose of including this scale was to determine whether behavior in my study aligned with the strength model or the nonlimited resource theory. We already know that some people believe their willpower is limited and others believe it is nonlimited. However, according to the strength model, willpower does not eliminate the effects of depletion. No matter what people believes about themselves, a certain point, their energy resources will run low. If the Theories of Willpower scale does not affect results in this study, we would have evidence in support of the strength model, because willpower did not affect behavior after depletion. Likewise, if people who endorse a nonlimited resource mindset behave differently after depletion than people who believe their willpower is limited, then my study might support nonlimited resource theory.

\section{Process Model Measurement}

The process model states that a reduction in self-control seen after depletion is due to the fact that people could control themselves but choose not to after depletion. After depletion, they have less desire to do things they have to take care of and more desire to relax and unwind despite their responsibilities. However, according to the process model, people could force themselves to maintain self-control after depletion, but they just usually choose not to force themselves to exert the self-control (Inzlicht, Schmeichel, \& Macrae, 2014). In contrast, in the strength model, self-control diminishes 
after depletion and people would not be able to simply force themselves to maintain selfcontrol.

While I maintained my hypothesis that the strength model will frame my findings in this study, I measured whether the process model was a better fit. A simple two-item scale measured this, and it was administered right after depletion and before the reward sensitivity task. Participants indicated on a 7-point scale how much they agreed with the following questions. The first question was "How hard do you plan to work on the next task?" The second question was , "How much do you care about doing your best on the next task?" If the responses to these two questions correlated with results on my study, I decided to consider how the process model may be related to my findings.

\section{Monetary Choice Questionnaire}

The participants completed the Monetary Choice Questionnaire (MCQ) (Kirby \& Maracovic, 1996). This 27-item questionnaire asks participants a series of questions about whether they would prefer a smaller amount of money now or a larger amount of money at a later time, varying both the amounts of money and amount of time the participant would have to wait for the larger amount of money. Example items include “Would you prefer $\$ 25$ today, or \$30 in 80 days?” and “Would you prefer $\$ 33$ today, or $\$ 80$ in 14 days?”. MCQ scores were used to measure impulsivity in this study. We scored the inventory by giving participants 0 points every time they chose the smaller amount of money and 1 point every time they chose the larger amount of money. We summed these scores in our analysis.

Crossing Out E's Task 
In the crossing out e's task, participants receive a page of a journal article and are instructed to cross out all of the letter e's on that page. This helps them form a habit of crossing out e's. Next, participants receive another page of a journal article, but the rules for crossing out e's becomes more complex. This task has been used to induce mental fatigue (see Baumeister, 1998; DeWall, 2008; Tice et al., 2007).

An electronic version of the Crossing Out E's task was used in the multi-lab preregistered replication of the depletion effect conducted in 2015 called the Registered Replication Report (RRR) (Hagger et al., 2015). The depletion effect failed to replicate with this task. However, I still chose to use the task because my task is has a key difference from the task used in the replication study. The RRR did not include participants forming the initial habit of crossing out e's before switching to more complicated rules. Therefore, there was no habit for the participants to break, which was a crux of the depleting effects of this task (Baumeister \& Vohs, 2016). The fact remains that this classic task has shown to have significant depleting effects in multiple studies (see DeWall, 2008; Galliott, Zell, \& Baumeister, 2014; Vohs, Baumeister \& Schmeichel, 2012).

\section{Making Choices Task}

The Making Choices task requires participants to choose between a series of pairs of similar items. Participants view 100 pairs of items that are very similar and have to decide which one they would rather buy. Each item is worth less than $\$ 20$. This type of task has been used to successfully induce depletion (Vohs, Baumeister, \& Schmeichel, 2012).

Stroop Task 
In the Stroop task (Stroop, 1939), participants see words for colors, such as yellow or blue. However, the word is printed in a different color font. For example, the word "yellow" might be printed in a blue font. The participant use a keyboard to indicate the font color the word is printed in. The Stroop task has been widely used by other researchers to deplete self-control resources (Inzlicht \& Gutsell, 2007; Mead et al., 2009).

\section{Progressive Ratio Task}

The progressive ratio task has been used widely to study reward motivation (Chelonis, Gravelin, \& Paule, 2011; Paule et al., 1999). In this task, participants earn points for clicking the computer's mouse. Points are earned in a progressive schedule. First, participants need to click the mouse 50 times to receive a point, then 100 times, then 150 times, continuing to press an additional 50 times to receive each point. More points earned signify greater reward motivation.

\section{Procedure}

Before arriving to the laboratory, participants were already assigned a condition at random. Each participant received either anodal stimulation or sham (control) stimulation with the tDCS device.

After arriving in the laboratory, participants completed the informed consent process, including an exclusion criteria screening in addition to the one they already completed online before the study. Next, they completed the Theories of Willpower scale and the MCQ. After that, the tDCS electrodes were attached.

By random assignment, participants experienced either excitatory or sham tDCS over the rVLPFC. To stimulate the rVLPFC, direct current was applied to the rVLPFC using a constant current regulator (DC-STIMULATOR, NeuroConn GmbH, Germany). 
The current was transferred using a saline-soaked pair of surface sponge electrodes placed on the participant's scalp. The stimulation (anode) electrode was placed over F6 (Montreal Neurological Institute coordinates: 58, 30, 8), whereas the reference (cathode) electrode was placed over the controlateral supraorbital area. To increase focality of stimulation, the stimulation electrode was $25 \mathrm{~cm}^{2}$ and the reference electrode was $35 \mathrm{~cm}^{2}$. All participants were told that they would receive either real or sham (placebo) stimulation for 25 minutes. Only half actually received a constant current of $1.5 \mathrm{~mA}$ (excitatory stimulation), while the other half received sham stimulation.

After the electrodes were comfortably attached, the stimulation began. For the first 10 minutes of stimulation, participants watched a nature video as a filler task. The tDCS was beginning to build up in the brain during this time. At the 10-minute mark, participants began depletion exercises for the remaining 15 minutes of stimulation. They performed the crossing out e's task, the making choices task, and the Stroop task. After the 15 minutes had elapsed, participants stopped these exercises, regardless of whether they have fully completed all three tasks.

After 25 minutes of stimulation, the tDCS ramped down and turn off, and the electrodes were removed from the participants. Next, they completed the 2-item process model measure. They then received instructions for the progressive ratio task and completed it. After the progressive ratio task, participants were fully debriefed.

\section{Planned Analyses}

\section{Power analysis}

I conducted an a priori power analysis to determine the sample size needed for this study. To begin, I needed to predict the size of effect both tDCS and MCQ score 
would have on the reward sensitivity task. To best determine the effect tDCS would have on reward sensitivity, I looked to a more general meta-analysis of the effect size of tDCS on cognitive tasks. This meta-analysis indicated that the effect size of tDCS on cognitive tasks was equal to a Cohen's f ${ }^{2}$ effect size of 0.15 (Jacobson, Koslowsky, \& Lavidor, 2012), which is considered to be a medium effect size.

To determine the effect size of MCQ score on reward sensitivity, I could look back to my preliminary study on the effect of depletion and MCQ score on reward sensitivity. This was advantageous because we could look at how MCQ score predicted PR performance on the exact same task that will be used in the current study. Filtering the data to only look at the depleted people in the preliminary study, I determined that the effect size of MCQ on reward sensitivity was equal to a Cohen's $\mathrm{f}^{2}$ effect size of 0.03 , which is considered to be small.

A good parallel to determine the effect size of a possible interaction between tDCS and MCQ score on reward sensitivity also comes from the preliminary study. In the preliminary study, people received depletion or no depletion, and then the moderating effect of MCQ score on reward sensitivity was studied. Depletion or no depletion in some ways mimics my study where everyone is depleted, but half receive brain stimulation. In theory, the people who receive stimulation should behave more like the non-depleted people in the preliminary study, because we expected the cognitive effects of tDCS on the rVLFPC to partially counteract the effect of depletion on reward sensitivity. With that in mind, we looked at the effect size of the interaction between depletion condition and MCQ score on reward sensitivity in the preliminary study. The effect size of the 
interaction was equal to a Cohen's $\mathrm{f}^{2}$ effect size of 0.04 , which is considered to be a small effect size.

The power analysis was conducted in G Power. The estimated effect sizes were entered into this analysis. To conduct a study with $80 \%$ power, we would need 53 people to find an effect of tDCS, 233 people to find an effect of MCQ, and 277 people to detect an interaction between tDCS and MCQ. Because of the feasibility of conducting a large number of brain stimulations, we planned to use a sample size of 200 for $64 \%$ power. In actuality, we were able to test 224 participants. Looking at reviews of tDCS studies, in general, tDCS studies typically have 50 or fewer participants (see Berlim et al., 2013; Filmer, Dux, \& Mattingly, 2014; Kalu et al., 2012). Thus, this is the largest ever tDCS experiment used to test social psychological theories.

\section{Statistical Analysis}

We hypothesized a two-way interaction between stimulation and MCQ score (see Figure 2). We predicted that with sham stimulation, only people with low MCQ scores (indicating high trait impulsivity) would demonstrate elevated motivation for rewards. This would replicate the results of the preliminary study, where depleted people who had low MCQ scores showed elevated motivation for rewards. For participants who received anodal stimulation, we did not expect to see elevated motivation for rewards in people regardless of MCQ score. We expected that anodal stimulation would partially or fully protect from the effects of depletion that can result in elevated motivation for rewards.

To test these hypotheses, we used a regression analysis and tested for moderation. The predictors were anodal versus sham stimulation and MCQ score. We tested the moderating effects of the MCQ by testing these scores at 1 standard deviation above and 
1 standard deviation below the mean MCQ score in the full regression model (see Aiken \& West, 1991). We planned to remove outliers that were more than 3 standard deviations from the mean. We did not find any outliers in the data.

\section{Results}

We hypothesized a two-way interaction between stimulation and MCQ score. However, we did not find this interaction, as MCQ score did not affect performance on the PR task. Contrary to our predictions, brain stimulation led to more motivation on the PR task, not less. This effect only emerged under certain conditions. Before performing the PR task, we asked participants how hard they planned to work on the task on a 1 to 7 Likert scale. tDCS only improved the performance of participants who planned to work hard on the task ( 1 standard deviation above the mean as compared to other participants in the study). Figure 3 shows this interaction.

We conducted a hierarchical regression analysis where brain stimulation and how hard participants planned to work on the PR task predicted performance on the PR task. There was a significant interaction between tDCS and how hard participants planned to work, $\mathrm{B}=0.20, \mathrm{t}(220)=2.12, \mathrm{p}=.035$. The same interaction was seen when examining PR

presses instead of PR points, though this interaction was marginally significant, $B=60.16$, $t(220)=1.95, p=.053$. The following tests of this interaction will refer to the effects of tDCS and how hard participants planned to work on how many points participants earned on the PR task through work.

To interpret this interaction, we tested the simple slopes of how hard participants planned to work at relatively low and high scores on this measure (one standard deviation above and below the mean, Aiken \& West, 1991). First, we can examine just the people 
who got the sham stimulation after depletion. For all intents and purposes, these people did not receive brain stimulation. The slope of the sham line was not significant, $\mathrm{B}=-0.08$, $\mathrm{t}(114)=-1.19, \mathrm{p}=.236$. This means that without brain stimulation, how hard you plan to work on the PR task does not predict your actual work output when you are depleted.

Next, we can examine just the people who got real brain stimulation. The slope of the tDCS line was marginally significant, $\mathrm{B}=0.12, \mathrm{t}(106)=1.88, \mathrm{p}=.063$. This means that if you get brain stimulation, how hard you plan to work on the PR task does predict your actual work output. If you plan to work hard, you can actually do more work with the help of the brain stimulation.

We also tested the simple effects of brain stimulation at high and low levels of how hard participants planned to work on the PR task. First, we can examine people who indicate they did not plan to work very hard, as defined by one standard deviation below the mean on this measure. There was no performance difference between people who got brain stimulation and the sham if they did not plan to work very hard, $\mathrm{B}=-0.08, \mathrm{t}(220)=-$ $1.29, \mathrm{p}=.371$. tDCS could not help people perform better if they did not actually plan to work hard.

Finally, we can examine people who did plan to work very hard, as indicated by one standard deviation above the mean on that measure. People who got brain stimulation were able to do more work on the PR task than their sham counterparts, $B=0.29$, $t(220)=2.10, p=.034$. In summary, brain stimulation could help participants perform more work on the PR task, but only if they actually planned to work hard on the task.

\section{Discussion}


This study was the first of its kind to modulate self-control in the brain in an effort to understand the mechanisms behind depletion and motivation. While fMRI studies have shown the role of self-control regions in the brain as they relate to depletion (Cohen et al., 2013; Riva et al., 2014; Welborn et al., 2015), this study used a new tool to modulate brain activity in a self-control region of the brain during depletion to see if this region could protect from the effects of depletion. Certainly, our results show that stimulating the rVLPFC in depleted people resulted in more work output on the subsequent PR task. However, this effect was only found when participants actually planned to work hard on the PR task.

These results suggest that brain stimulation to the rVLPFC reduced or eliminated the effects of depletion we typically see. When people did not receive the help of tDCS and only got sham stimulation, their motivation alone could not help them do more work on the PR task. This supports the strength model of self-control, not the process model, because motivation could not increase work output in these depleted individuals.

When people did receive the help of tDCS, they were able to out-perform their sham stimulation counterparts when they were motivated to do so. In other words, they acted like they were not depleted if they were motivated. This result provides evidence for the important role of the rVLPFC with regard to mental fatigue. In this case, when we were able to stimulate it to work better, people acted like they were not depleted. Their motivation did help them increase their work output on the PR task, in contrast to their depleted counterparts who did not receive extra help from tDCS. Because people act less depleted when the rVLPFC is more active, this brain region seems to be key in the process of mental fatigue. 
We did not find evidence for the nonlimited theory of self-control. A growth mindset about willpower did not increase work output on the PR task. Our results best support the strength model of self-control. With just sham stimulation, depleted people all performed statistically the same on the PR task despite growth mindset or motivation to perform well on the task. Even with brain stimulation, a growth mindset about willpower did not increase work output on the PR task. However, it is interesting to note that for the people who received brain stimulation, motivation could help them do better on the PR task. This is probably because the brain stimulation helped them feel less depleted as their rVLPFCs were working better.

These results suggest a combination of motivation and ability were needed to overcome the effects of depletion. In this case, motivation to perform the PR task and increased ability via the brain stimulation formed a potent combination resulting the ability to actually do more work. This finding echoes a recent fMRI study that also found a combination of motivation and ability key for accuracy of work output on the subsequent task (Luethi et al., in press). In that study, people who underwent depletion had more activity in the prefrontal cortex than their non-depleted counterparts. However, although this neural effect was seen across the group of depleted participants, motivation drove their behavioral results, with more motivated individuals being more accurate on the subsequent task (Luethi et al., in press). Taken together, these findings suggest that a combination of motivation to work hard and a greater ability to do so helps depleted people do more work to reach their goals.

\section{Different results than expected}


The preliminary study found that depletion and impulsivity interacted to predict performance on the PR task. We found that depleted people were more responsive on the PR task than not-depleted people if they were also impulsive. We thought that the depletion and impulsivity were combining to encourage them to seek the reward of points on the PR task.

In this study, impulsivity did not predict performance on the PR task. Depleted people who received brain stimulation performed more work on the PR task than people who were depleted without receiving brain stimulation. The people who received brain stimulation behaved how we would expect a non-depleted person to behave. In the preliminary study, the depleted people were more responsive on the PR task, while in this study, the people who received brain stimulation were more responsive on the PR task. These results suggest replication is needed to further understand this apparent contradiction.

In the previous study, we viewed the PR task as a measure of reward sensitivity. However, the only reward you can earn in this particular PR task is points. This is perhaps a rather meaningless reward. Nevertheless, to perform the PR task, you have to work hard. Most participants press the mouse about 1000 times within a five-minute period. Our consent forms even warn participants that their hands may cramp up from the sheer workload of the task. The previous results made it seem like the task was measuring reward sensitivity. However, in light of these results, and using common sense, it actually seems like the task measures motivation to perform work output. After all, participants do not earn anything fun. They simply press the mouse as fast as they can for five minutes and earn about 4-7 points along the way. Therefore, we have changed how we view what 
the task is really measuring in light of the new information we have learned in this study. However, it is important to note inconsistencies of the results of the two studies. Replication will certainly be essential in understanding what these results truly mean.

\section{Limitations}

One limitation in this study relates to dosage and length of stimulation. Previous studies vary dosage between 1 and $2 \mathrm{~mA}$, and duration of stimulation varies wildly (see Filmer, Dux, \& Mattingly, 2014). Some studies examine the effect of tDCS while it attached (online stimulation), while others examine it after it is detached (offline stimulation) in short (minutes to hours) and long (days to weeks) time frames (Filmer, Dux, \& Mattingly, 2014). We choose a moderate approach, using $1.5 \mathrm{~mA}$ stimulation for 25 minutes, performing tasks while online, and performing the dependent measure in a brief offline period. However, all of these factors can affect results. There is not yet a gold standard for what parameters to use in tDCS.

In addition, my study only uses anodal stimulation and excludes cathodal stimulation. While we are more interested in ameliorating depletion rather than making it worse, it would be interesting to see how cathodal stimulation affected results in a future study. It could result in reward sensitivity that is even greater than what is typically seen after depletion because the link between the rVLPFC and reward centers in the brain would theoretically be further disrupted.

We targeted the rVLPFC in this study, as there is evidence strongly connecting it to self-control (Cohen et al., 2013; Lieberman, 2009; Welborn et al., 2015). However, other researchers have targeted other parts of the prefrontal cortex including the DLPFC in similar research (Boggio et al., 2016; Loftus et al., 2015). We believe we are targeting 
the area of the PFC most related to self-control, but future research could compare montages on other parts of the PFC including the DLPFC.

\section{Future directions}

This study used tDCS as a tool to understand the neural mechanisms behind depletion. We stimulated the rVLPFC, a self-control region in the brain, while people were undergoing depletion. In this way, we increased people's ability to exercise selfcontrol. We found that when this region was able to work better, people acted less mentally fatigued during the subsequent task. However, this effect was only found in individuals who were motivated to perform well on that task. A combination of motivation and ability was needed to increase work output on the subsequent task.

This study provides evidence for the important role of the rVLPFC in depletion. fMRI studies have shown us that the rVLPFC puts the brakes on the nucleus accumbens, a reward area of the brain (Lieberman, 2007). When people are mentally fatigued, the rVLPFC does not work as well (Cohen et al., 2013; Riva et al., 2014; Welborn et al., 2015). The consequence of this is that reward areas of the brain like the nucleus accumbens start to take over during depletion (see Heatherson \& Wagner, 2011 for an explanation of the relationship between the rVLPFC and the nucleus accumbens). With tDCS, we were successfully able to disrupt this process by helping the rVLPFC work better. This helps us understand the key role of the rVLPFC in the depletion process.

Our laboratory is currently investigating the connection between these two brain regions with fMRI work. We are also using diffusion tensor imaging, a technology that can show us how thick the tracts of axons connecting these two areas is. A thicker connection means the areas work well together, and a thinner connection means they 
have less communication. We are currently examining how individual differences in the thickness of these tracts affect behavior relating to self-control.

In addition to replicating the present experiment, we are also interested in examining how brain stimulation to the rVLPFC can affect constructs other than motivation and work output. Currently, we are conducting a study that examines if tDCS can help reduce risk-taking behavior. We hope to harness the utility of tDCS in multiple arenas to better understand how the brain works. In addition, tDCS itself is beginning to be used as a therapeutic instrument. Therefore, our research helps us understand the brain, but the brain stimulation itself can also directly help people.

Neuromodulation is not the wave of the future. This technology is available now and is likely to only increase in prevalence and utility. tDCS is already commercially available cheaply online, and people are trying to use it for all kinds of things including increasing athletic performance and augmenting learning. In this study, we found brain stimulation could help reduce the effects of mental fatigue. Our task as scientists is to harness this modern technology in a variety of different domains to help improve people's lives. 


\section{References}

Anker, J. J., Perry, J. L., Gliddon, L. A., \& Carroll, M. E. (2009). Impulsivity predicts the escalation of cocaine self-administration in rats. Pharmacology Biochemistry and Behavior, 93(3), 343-348.

Baron, A., \& Derenne, A. (2000). Progressive ratio schedules: Effects of later schedule requirements on earlier performances. Journal of the Experimental Analysis of Behavior, 73(3), 291-304.

Baumeister, R. F. (2002). Yielding to temptation: Self-control failure, impulsive purchasing, and consumer behavior. Journal of Consumer Research, 28(4), 670676.

Baumeister, R. F., Bratslavsky, E., Muraven, M., \& Tice, D. M. (1998). Ego depletion: is the active self a limited resource?. Journal of personality and social psychology, 74(5), 1252.

Baumeister, R. F., Muraven, M., \& Tice, D. M. (2000). Ego depletion: A resource model of volition, self-regulation, and controlled processing. Social cognition, 18(2), 130.

Baumeister, R. F., \& Vohs, K. D. (2016). Misguided effort with elusive implications. Perspectives on Psychological Science, 11(4), 574-575.

Ben-Shachar, D., Belmaker, R. H., Grisaru, N., \& Klein, E. (1997). Transcranial magnetic stimulation induces alterations in brain monoamines.Journal of Neural Transmission, 104(2-3), 191-197. 
Bennabi, D., Pedron, S., Haffen, E., Monnin, J., Peterschmitt, Y., \& Van Waes, V. (2014). Transcranial direct current stimulation for memory enhancement: from clinical research to animal models. Frontiers in systems neuroscience, 8, 159.

Berlim, M. T., Van den Eynde, F., \& Daskalakis, Z. J. (2013). Clinical utility of transcranial direct current stimulation (tDCS) for treating major depression: a systematic review and meta-analysis of randomized, double-blind and shamcontrolled trials. Journal of psychiatric research, 47(1), 1-7.

Boggio, P. S., Rêgo, G. G., Marques, L. M., \& Costa, T. L. (2016). Social Psychology and Noninvasive Electrical Stimulation. European Psychologist.

Boggio, P. S., Rocha, R. R., da Silva, M. T., \& Fregni, F. (2008). Differential modulatory effects of transcranial direct current stimulation on a facial expression go-no-go task in males and females. Neuroscience letters,447(2), 101-105.

Boggio, P. S., Zaghi, S., \& Fregni, F. (2009). Modulation of emotions associated with images of human pain using anodal transcranial direct current stimulation (tDCS). Neuropsychologia, 47(1), 212-217.

Brace, A., \& Yeomans, M. R. (2016). The reinforcing value of palatable snack foods and its relationship to subtypes of behavioural and self-report impulsivity. Eating behaviors, 21, 18-23.

Brunoni, A. R., Amadera, J., Berbel, B., Volz, M. S., Rizzerio, B. G., \& Fregni, F. (2011). A systematic review on reporting and assessment of adverse effects associated with transcranial direct current stimulation. International Journal of Neuropsychopharmacology, 14, 1133-1145 
Buckholtz, J. W., Treadway, M. T., Cowan, R. L., Woodward, N. D., Li, R., Ansari, M. S., ... \& Kessler, R. M. (2010). Dopaminergic network differences in human impulsivity. Science, 329(5991), 532-532.

Cabeza, R., \& Nyberg, L. (2000). Imaging cognition II: An empirical review of 275 PET and fMRI studies. Journal of cognitive neuroscience, 12(1), 1-47.

Carr, K. A., Lin, H., Fletcher, K. D., \& Epstein, L. H. (2014). Food reinforcement, dietary disinhibition and weight gain in nonobese adults.Obesity, 22(1), 254-259.

Chatzisarantis, N. L., \& Hagger, M. S. (2015). Unsuccessful attempts to replicate effects of self control operations and glucose on ego-depletion pose an interesting research question that demands explanation. Appetite, 84, 328-329.

Chelonis, J. J., Gravelin, C. R., \& Paule, M. G. (2011). Assessing motivation in children using a progressive ratio task. Behavioural processes, 87(2), 203-209.

Chelonis, J. J., Johnson, T. A., Ferguson, S. A., Berry, K. J., Kubacak, B., Edwards, M. C., \& Paule, M. G. (2011). Effect of methylphenidate on motivation in children with attention-deficit/hyperactivity disorder. Experimental and clinical psychopharmacology, 19(2), 145.

Chester, D. S., \& DeWall, C. N. (2014). Prefrontal recruitment during social rejection predicts greater subsequent self-regulatory imbalance and impairment: neural and longitudinal evidence. NeuroImage, 101, 485-493.

Civai, C., Crescentini, C., Rustichini, A., \& Rumiati, R. I. (2012). Equality versus selfinterest in the brain: differential roles of anterior insula and medial prefrontal cortex. Neuroimage, 62(1), 102-112. 
Cohen, J. R., Berkman, E. T., \& Lieberman, M. D. (2013). Intentional and incidental selfcontrol in ventrolateral PFC. Principles of Frontal Lobe Function, 417-440.

Crews, F. T., \& Boettiger, C. A. (2009). Impulsivity, frontal lobes and risk for addiction. Pharmacology Biochemistry and Behavior, 93(3), 237-247.

Czachowski, C. L., \& Samson, H. H. (1999). Breakpoint Determination and Ethanol SelfAdministration Using an Across-Session Progressive Ratio Procedure in the Rat. Alcoholism: Clinical and Experimental Research,23(10), 1580-1586.

Dambacher, F., Schuhmann, T., Lobbestael, J., Arntz, A., Brugman, S., \& Sack, A. T. (2015). Reducing proactive aggression through non-invasive brain stimulation. Social cognitive and affective neuroscience, nsv018.

Depoortere, R. Y., Li, D. H., Lane, J. D., \& Emmett-Oglesby, M. W. (1993). Parameters of self-administration of cocaine in rats under a progressive-ratio schedule. Pharmacology Biochemistry and Behavior, 45(3), 539-548.

Der-Avakian, A., \& Markou, A. (2012). The neurobiology of anhedonia and other reward-related deficits. Trends in neurosciences, 35(1), 68-77.

Diergaarde, L., Pattij, T., Poortvliet, I., Hogenboom, F., de Vries, W., Schoffelmeer, A. N., \& De Vries, T. J. (2008). Impulsive choice and impulsive action predict vulnerability to distinct stages of nicotine seeking in rats.Biological psychiatry, 63(3), 301-308.

Epstein, L. H., Salvy, S. J., Carr, K. A., Dearing, K. K., \& Bickel, W. K. (2010). Food reinforcement, delay discounting and obesity. Physiology \& Behavior,100(5), 438-445. 
Evans, D. R., Boggero, I. A., \& Segerstrom, S. C. (2015). The nature of self-regulatory fatigue and "ego depletion" lessons from physical fatigue. Personality and Social Psychology Review, 1088868315597841.

Fecteau, S., Pascual-Leone, A., Zald, D. H., Liguori, P., Théoret, H., Boggio, P. S., \& Fregni, F. (2007). Activation of prefrontal cortex by transcranial direct current stimulation reduces appetite for risk during ambiguous decision making. The Journal of neuroscience, 27(23), 6212-6218.

Ferrucci, R., Giannicola, G., Rosa, M., Fumagalli, M., Boggio, P. S., Hallett, M., ... \& Priori, A. (2012). Cerebellum and processing of negative facial emotions: cerebellar transcranial DC stimulation specifically enhances the emotional recognition of facial anger and sadness. Cognition \& emotion,26(5), 786-799.

Fertonani A, \& Miniussi C (2016). Transcranial Electrical Stimulation: What We Know and Do Not Know About Mechanisms. The Neuroscientist. PMID: 26873962.

Filmer, H. L., Dux, P. E., \& Mattingley, J. B. (2014). Applications of transcranial direct current stimulation for understanding brain function. Trends in neurosciences, 37(12), 742-753.

Gailliot, M. T., Baumeister, R. F., DeWall, C. N., Maner, J. K., Plant, E. A., Tice, D. M., ... \& Schmeichel, B. J. (2007). Self-control relies on glucose as a limited energy source: willpower is more than a metaphor. Journal of personality and social psychology, 92(2), 325 .

Gailliot, M. T., Zell, A., \& Baumeister, R. F. (2014). Having Used Self-Control Reduces Emotion Regulation -Emotion Regulation as Relying on Interchangeably Used “Self-Control Energy”. Open Access Library Journal, 1(08), 1. 
Hagger, M. S., \& Chatzisarantis, N. L. (2013). The sweet taste of success the presence of glucose in the oral cavity moderates the depletion of self-control resources. Personality and Social Psychology Bulletin, 39(1), 28-42.

Hagger, M. S., \& Chatzisarantis, N. L. (2013). The strength model of self-control: recent advances and implications for public health. In Social Neuroscience and Public Health (pp. 123-139). Springer New York.

Hagger, M. S., Chatzisarantis, N. L., Alberts, H., Anggono, C. O., Batailler, C., Birt, A., \& Zwienenberg, M. (2015). A multi-lab pre-registered replication of the egodepletion effect. Perspectives on Psychological Science, 2.

Hagger, M. S., Wood, C., Stiff, C., \& Chatzisarantis, N. L. (2010). Ego depletion and the strength model of self-control: a meta-analysis. Psychological bulletin, 136(4), 495.

Hare, T. A., Camerer, C. F., \& Rangel, A. (2009). Self-control in decision-making involves modulation of the vmPFC valuation system. Science,324(5927), 646648.

Harty, S., Robertson, I. H., Miniussi, C., Sheehy, O. C., Devine, C. A., McCreery, S., \& O'Connell, R. G. (2014). Transcranial direct current stimulation over right dorsolateral prefrontal cortex enhances error awareness in older age. The Journal of Neuroscience, 34(10), 3646-3652.

Hodos, W. (1961). Progressive ratio as a measure of reward strength. Science, 134(3483), 943-944.

Hofmann, W., Rauch, W., \& Gawronski, B. (2007). And deplete us not into temptation: Automatic attitudes, dietary restraint, and self-regulatory resources as 
determinants of eating behavior. Journal of Experimental Social Psychology, 43(3), 497-504.

Inzlicht M., Gervais W. M., Berkman E. T. (2016). Bias-correction techniques alone cannot determine whether ego depletion is different from zero: Comment on Carter, Kofler, Forster, and McCullough, 2015. Manuscript submitted for publication.

Inzlicht, M., \& Gutsell, J. N. (2007). Running on empty neural signals for self-control failure. Psychological Science, 18(11), 933-937.

Inzlicht, M., \& Schmeichel, B. J. (2012). What is ego depletion? Toward a mechanistic revision of the resource model of self-control. Perspectives on Psychological Science, 7(5), 450-463.

Inzlicht, M., Schmeichel, B. J., \& Macrae, C. N. (2014). Why self-control seems (but may not be) limited. Trends in cognitive sciences, 18(3), 127-133.

Jacobson, L., Koslowsky, M., \& Lavidor, M. (2012). tDCS polarity effects in motor and cognitive domains: a meta-analytical review. Experimental brain research, 216(1), 1-10.

Job, V., Walton, G. M., Bernecker, K., \& Dweck, C. S. (2015). Implicit theories about willpower predict self-regulation and grades in everyday life. Journal of Personality and Social Psychology, 108(4), 637.

Kahan, D., Polivy, J., \& Herman, C. P. (2003). Conformity and dietary disinhibition: A test of the ego-strength model of selfregulation. International Journal of Eating Disorders, 33(2), 165-171. 
Kalu, U. G., Sexton, C. E., Loo, C. K., \& Ebmeier, K. P. (2012). Transcranial direct current stimulation in the treatment of major depression: a metaanalysis. Psychological medicine, 42(09), 1791-1800.

Kanfer, F. H., \& Karoly, P. (1972). Self-control: A behavioristic excursion into the lion's den. Behavior therapy, 3(3), 398-416.

Kekic, M., McClelland, J., Campbell, I., Nestler, S., Rubia, K., David, A. S., \& Schmidt, U. (2014). The effects of prefrontal cortex transcranial direct current stimulation (tDCS) on food craving and temporal discounting in women with frequent food cravings. Appetite, 78, 55-62.

Kelley, N. J., Hortensius, R., \& Harmon-Jones, E. (2013). When anger leads to rumination induction of relative right frontal cortical activity with transcranial direct current stimulation increases anger-related rumination. Psychological science, 24(4), 475-481.

Kirby, K. N., \& Maraković, N. N. (1996). Delay-discounting probabilistic rewards: Rates decrease as amounts increase. Psychonomic bulletin \& review, 3(1), 100-104.

Klimesch, W. (1999). EEG alpha and theta oscillations reflect cognitive and memory performance: a review and analysis. Brain research reviews, 29(2), 169-195.

Knardahl, S., \& Sagvolden, T. (1979). Open-field behavior of spontaneously hypertensive rats. Behavioral and neural biology, 27(2), 187-200.

Knudsen, E. I. (2004). Sensitive periods in the development of the brain and behavior. Journal of cognitive neuroscience, 16(8), 1412-1425.

Kollins, S. H., English, J. S., Roley, M. E., O’Brien, B., Blair, J., Lane, S. D., \& McClernon, F. J. (2013). Effects of smoking abstinence on smoking-reinforced 
responding, withdrawal, and cognition in adults with and without attention deficit hyperactivity disorder. Psychopharmacology, 227(1), 19-30.

Kreek, M. J., Nielsen, D. A., Butelman, E. R., \& LaForge, K. S. (2005). Genetic influences on impulsivity, risk taking, stress responsivity and vulnerability to drug abuse and addiction. Nature neuroscience, 8(11), 1450-1457.

Lange, F., Seer, C., Rapior, M., Rose, J., \& Eggert, F. (2014). Turn it all you want: Still no effect of sugar consumption on ego depletion. Journal of European Psychology Students, 5(3).

Lapenta, O. M., Di Sierve, K., de Macedo, E. C., Fregni, F., \& Boggio, P. S. (2014). Transcranial direct current stimulation modulates ERP-indexed inhibitory control and reduces food consumption. Appetite, 83, 42-48.

Lieberman, M. D., \& Eisenberger, N. I. (2008). The pains and pleasures of social life: a social cognitive neuroscience approach. NeuroLeadership Journal, 1, 1-9.

Loftus, A. M., Yalcin, O., Baughman, F. D., Vanman, E. J., \& Hagger, M. S. (2015). The impact of transcranial direct current stimulation on inhibitory control in young adults. Brain and behavior, 5(5).

Luculano, T., \& Kadosh, R. C. (2013). The mental cost of cognitive enhancement. The Journal of Neuroscience, 33(10), 4482-4486.

Luethi, Friese, Binder, Boesiger, Luechinger, \& Rasch (in press). Motivational incentives lead to a strong increase in lateral prefrontal activity after self-control exertion. Society for Cognitive and Affective Neuroscience, 11(10), 1618-1626. 
MacKenzie, M. J., \& Baumeister, R. F. (2015). Self-Regulatory Strength and Mindfulness. In Handbook of Mindfulness and Self-Regulation (pp. 95-105). Springer New York.

Martin, D. M., Liu, R., Alonzo, A., Green, M., Player, M. J., Sachdev, P., \& Loo, C. K. (2013). Can transcranial direct current stimulation enhance outcomes from cognitive training? A randomized controlled trial in healthy participants. International Journal of Neuropsychopharmacology, 16(9), 19271936.

Masten, C. L., Eisenberger, N. I., Borofsky, L. A., Pfeifer, J. H., McNealy, K., Mazziotta, J. C., \& Dapretto, M. (2009). Neural correlates of social exclusion during adolescence: understanding the distress of peer rejection. Social cognitive and affective neuroscience, 4(2), 143-157.

McCarty, R., \& Kopin, I. J. (1979). Patterns of behavioral development in spontaneously hypertensive rats and Wistar-Kyoto normotensive controls. Developmental Psychobiology, 12(3), 239-243.

Mead, N. L., Baumeister, R. F., Gino, F., Schweitzer, M. E., \& Ariely, D. (2009). Too tired to tell the truth: Self-control resource depletion and dishonesty. Journal of experimental social psychology, 45(3), 594-597.

Miller, E. M., Walton, G. M., Dweck, C. S., Job, V., Trzesniewski, K. H., \& McClure, S. M. (2012). Theories of willpower affect sustained learning. PloS one, 7(6), e38680.

Miller, E. M., Pomerleau, F., Huettl, P., Gerhardt, G. A., \& Glaser, P. E. (2014). Aberrant glutamate signaling in the prefrontal cortex and striatum of the spontaneously 
hypertensive rat model of attention-deficit/hyperactivity

disorder. Psychopharmacology, 231(15), 3019-3029.

Miras, A. D., Jackson, R. N., Jackson, S. N., Goldstone, A. P., Olbers, T., Hackenberg, T., ... \& le Roux, C. W. (2012). Gastric bypass surgery for obesity decreases the reward value of a sweet-fat stimulus as assessed in a progressive ratio task. The American journal of clinical nutrition, 96(3), 467-473.

Monai H, Ohkura M, Tanaka M, Oe Y, Konno A, Hirai H, Mikoshiba K, Itohara S, Nakai J, Iwai Y, \& Hirase H (2016). Calcium imaging reveals glial involvement in transcranial direct current stimulation-induced plasticity in mouse brain. Nature communications, 7. PMID: 27000523

Muraven, M., Collins, R. L., \& Neinhaus, K. (2002). Self-control and alcohol restraint: an initial application of the self-control strength model. Psychology of Addictive Behaviors, 16(2), 113.

Muraven, M., \& Baumeister, R. F. (2000). Self-regulation and depletion of limited resources: Does self-control resemble a muscle?. Psychological bulletin, 126(2), 247.

Muraven, M., \& Slessareva, E. (2003). Mechanisms of self-control failure: Motivation and limited resources. Personality and Social Psychology Bulletin,29(7), 894-906.

Myers, M. M., Musty, R. E., \& Hendley, E. D. (1982). Attenuation of hyperactivity in the spontaneously hypertensive rat by amphetamine. Behavioral and neural biology, 34(1), 42-54.

Okamoto, K., \& Aoki, K. (1963). Development of a strain of spontaneously hypertensive rats. Japanese circulation journal, 27(3), 282-293. 
Paule, M. G., Chelonis, J. J., Buffalo, E. A., Blake, D. J., \& Casey, P. H. (1999). Operant test battery performance in children: correlation with IQ. Neurotoxicology and Teratology, 21(3), 223-230.

Paule, M. G., Forrester, T. M., Maher, M. A., Cranmer, J. M., \& Allen, R. R. (1990). Monkey versus human performance in the NCTR operant test battery. Neurotoxicology and teratology, 12(5), 503-507.

Perry, J. L., Larson, E. B., German, J. P., Madden, G. J., \& Carroll, M. E. (2005). Impulsivity (delay discounting) as a predictor of acquisition of IV cocaine selfadministration in female rats. Psychopharmacology, 178(2-3), 193-201.

Richardson, N. R., \& Roberts, D. C. (1996). Progressive ratio schedules in drug selfadministration studies in rats: a method to evaluate reinforcing efficacy. Journal of neuroscience methods, 66(1), 1-11.

Riva, P., Lauro, L. J. R., DeWall, C. N., \& Bushman, B. J. (2012). Buffer the pain away stimulating the right ventrolateral prefrontal cortex reduces pain following social exclusion. Psychological science, 23(12), 1473-1475.

Riva, P., Lauro, L. J. R., DeWall, C. N., Chester, D. S., \& Bushman, B. J. (2014). Reducing aggressive responses to social exclusion using transcranial direct current stimulation (tDCS). Social cognitive and affective neuroscience, nsu053.

Rosenzweig, M. R., \& Bennett, E. L. (1996). Psychobiology of plasticity: effects of training and experience on brain and behavior. Behavioural brain research, 78(1), $57-65$. 
Rowlett, J. K. (2000). A labor-supply analysis of cocaine self-administration under progressive-ratio schedules: antecedents, methodologies, and perspectives. Psychopharmacology, 153(1), 1-16.

Ruff, C. C., Ugazio, G., \& Fehr, E. (2013). Changing social norm compliance with noninvasive brain stimulation. Science, 342(6157), 482-484.

Rush, C. R., Essman, W. D., Simpson, C. A., \& Baker, R. W. (2001). Reinforcing and Subject-Rated Effects of Methylphenidate and d-Amphetamine in Non-DrugAbusing Humans. Journal of clinical psychopharmacology, 21(3), 273-286.

Rusted, J. M., Mackee, A., Williams, R., \& Willner, P. (1998). Deprivation state but not nicotine content of the cigarette affects responding by smokers on a progressive ratio task. Psychopharmacology, 140(4), 411-417.

Sandrini, M., Fertonani, A., Cohen, L. G., \& Miniussi, C. (2012). Double dissociation of working memory load effects induced by bilateral parietal modulation. Neuropsychologia, 50(3), 396-402.

Schippers, M. C., Binnekade, R., Schoffelmeer, A. N., Pattij, T., \& De Vries, T. J. (2012). Unidirectional relationship between heroin self-administration and impulsive decision-making in rats. Psychopharmacology, 219(2), 443-452.

Schmeichel, B. J., Crowell, A., \& Harmon-Jones, E. (2015). Exercising self-control increases relative left frontal cortical activation. Social cognitive and affective neuroscience, nsv112.

Schmeichel, B. J., Harmon-Jones, C., \& Harmon-Jones, E. (2010). Exercising selfcontrol increases approach motivation. Journal of personality and social psychology, 99(1), 162. 
Schmeichel, B. J., Vohs, K. D., \& Baumeister, R. F. (2003). Intellectual performance and ego depletion: role of the self in logical reasoning and other information processing. Journal of personality and social psychology, 85(1), 33.

Spitzer, M., Fischbacher, U., Herrnberger, B., Grön, G., \& Fehr, E. (2007). The neural signature of social norm compliance. Neuron, 56(1), 185-196.

Sripada, C., Kessler, D., \& Jonides, J. (2014). Methylphenidate blocks effort-induced depletion of regulatory control in healthy volunteers. Psychological science, 0956797614526415.

Sterley, T. L., Howells, F. M., \& Russell, V. A. (2013). Evidence for reduced tonic levels of GABA in the hippocampus of an animal model of ADHD, the spontaneously hypertensive rat. Brain research, 1541, 52-60.

Stoops, W. W. (2008). Reinforcing effects of stimulants in humans: sensitivity of progressive-ratio schedules. Experimental and clinical psychopharmacology, 16(6), 503.

Stroop, J. R. (1935). Studies of interference in serial verbal reactions. Journal of experimental psychology, 18(6), 643.

Tice, D. M., Baumeister, R. F., Shmueli, D., \& Muraven, M. (2007). Restoring the self: Positive affect helps improve self-regulation following ego depletion. Journal of Experimental Social Psychology, 43(3), 379-384.

Underwood, E. (2016). Cadaver study challenges brain stimulation methods. Science, 352(6284), 397-397. 
Vadillo, M. A., Gold, N., \& Osman, M. (2016). The Bitter Truth About Sugar and Willpower The Limited Evidential Value of the Glucose Model of Ego Depletion. Psychological Science, 0956797616654911.

Vohs, K. D., Baumeister, R. F., \& Schmeichel, B. J. (2012). Motivation, personal beliefs, and limited resources all contribute to self-control. Journal of Experimental Social Psychology, 48(4), 943-947.

Vohs, K. D., Baumeister, R. F., Schmeichel, B. J., Twenge, J. M., Nelson, N. M., \& Tice, D. M. (2014). Making choices impairs subsequent self-control: a limited-resource account of decision making, self-regulation, and active initiative.

Vohs, K. D., \& Faber, R. J. (2007). Spent resources: Self-regulatory resource availability affects impulse buying. Journal of consumer research, 33(4), 537-547.

Vohs, K. D., \& Heatherton, T. F. (2000). Self-regulatory failure: A resource-depletion approach. Psychological science, 11(3), 249-254.

Wagner, D. D., Altman, M., Boswell, R. G., Kelley, W. M., \& Heatherton, T. F. (2013). Self-regulatory depletion enhances neural responses to rewards and impairs topdown control. Psychological science, 0956797613492985.

Winstanley, C. A., Dalley, J. W., Theobald, D. E., \& Robbins, T. W. (2003). Global 5HT depletion attenuates the ability of amphetamine to decrease impulsive choice on a delay-discounting task in rats. Psychopharmacology,170(3), 320-331.

Yanagisawa, K., Masui, K., Furutani, K., Nomura, M., Ura, M., \& Yoshida, H. (2011). Does higher general trust serve as a psychosocial buffer against social pain? An NIRS study of social exclusion. Social Neuroscience, 6(2), 190-197. 
Yang, M. T., Lu, D. H., Chen, J. C., \& Fu, W. M. (2015). Inhibition of hyperactivity and impulsivity by carbonic anhydrase inhibitors in spontaneously hypertensive rats, an animal model of ADHD. Psychopharmacology, 232(20), 3763-3772. 
Figure 1.

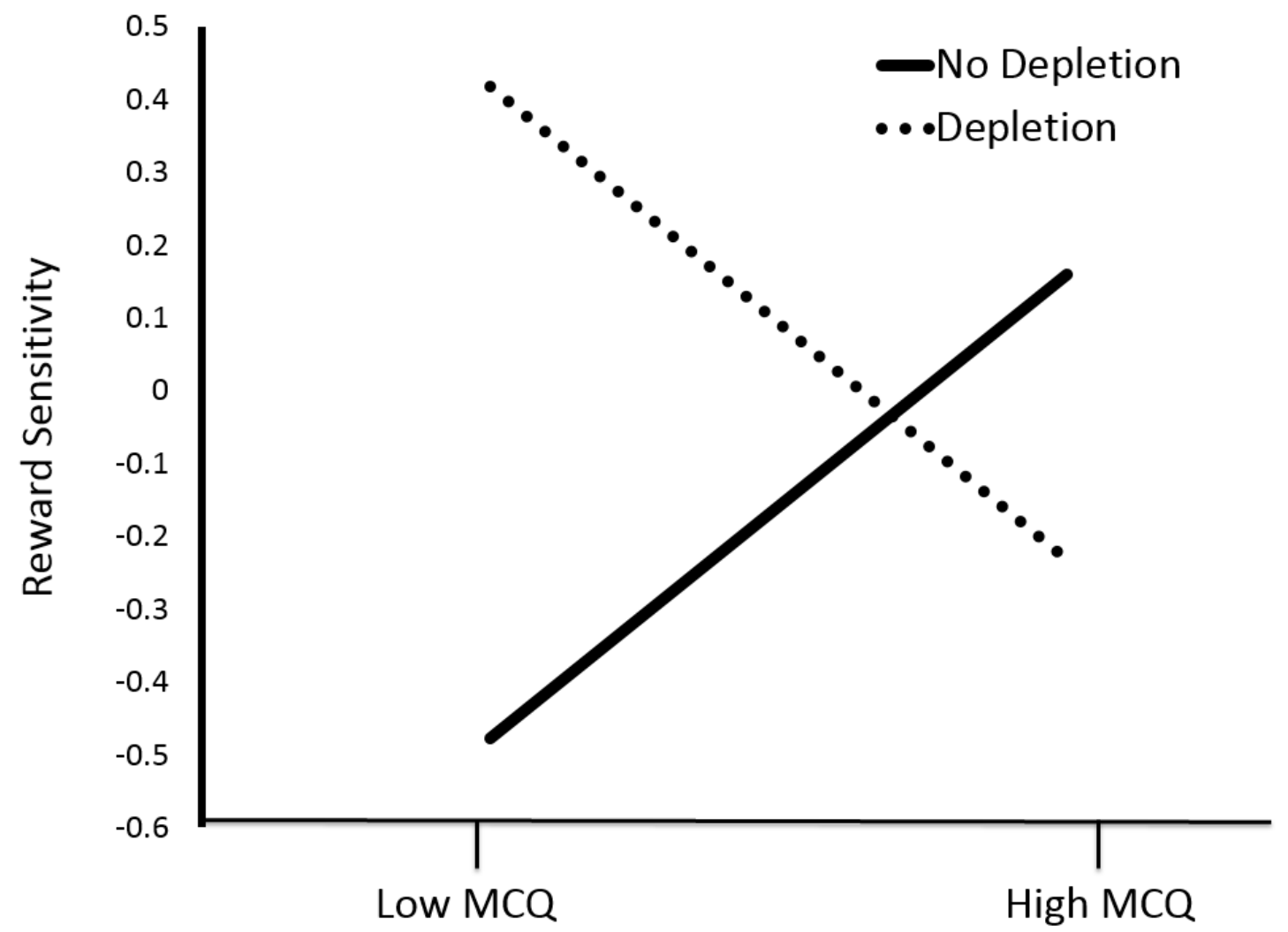

Interaction between MCQ and depletion on reward sensitivity in previous study. 
Figure 2 .

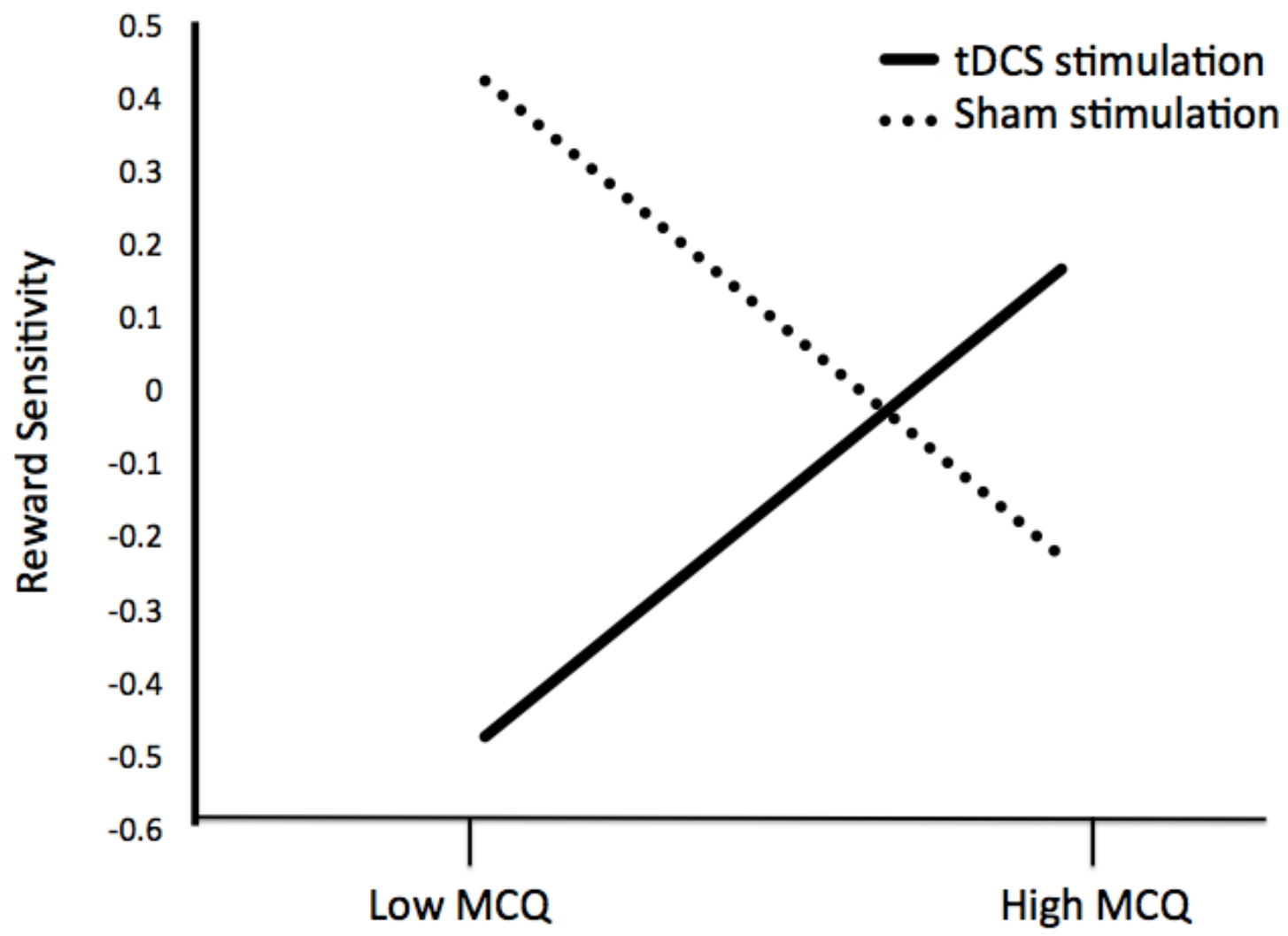

Expected interaction between tDCS and MCQ score on reward sensitivity. 
Figure 3.

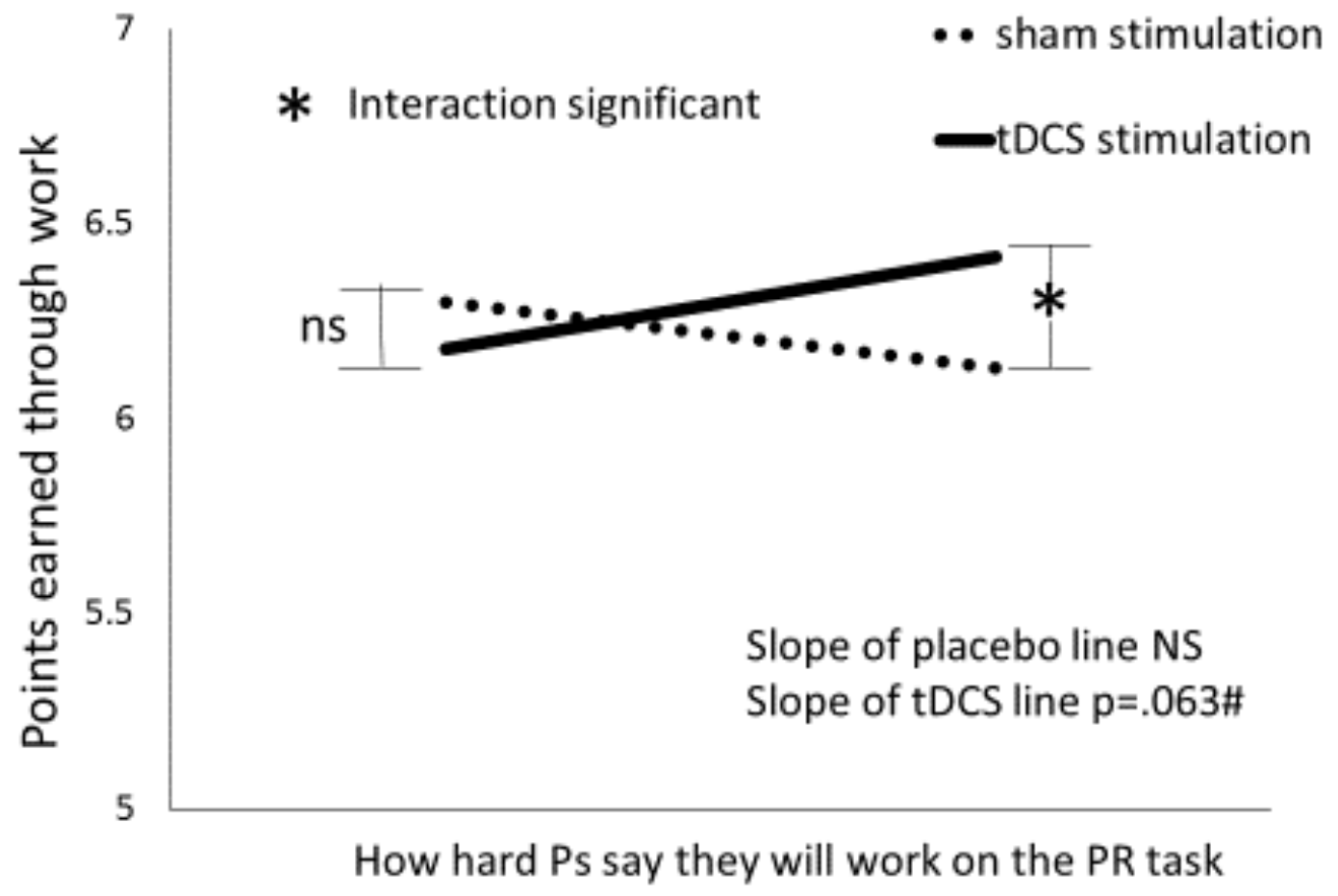

Interaction between brain stimulation and how hard participants planned to work on points earned through work on the PR task. 


\section{SARAH BETH BELL}

\section{EDUCATION}

University of Kentucky, 2015-present

Ph.D. candidate in Experimental Psychology

Mentor: Dr. Nathan DeWall

Hendrix College, 2008-2011

B.A. in Psychology, Gender studies

\section{PUBLICATIONS}

Enjaian, B.M. Bell, S.B., Whitt, Z. \& DeWall, C.N. (in press). Social-cognitive processes in the development of antisocial and violent behavior. In A.T. Vazonyi, D.J. Fannery, \& M. DeLisi (Eds.) The Cambridge Handbook of Violent Behavior and Aggression, $2^{\text {nd }}$ edition. Cambridge: Cambridge University Press.

Bell, S.B \& DeWall, C. N. (in press). Stigmatism and ostracism. In T. Shackelford \& V. Weekes-Shackelford (Eds.), Encyclopedia of Evolutionary Psychological Science. Springer International Publishing.

DeWall, C. N., Bell, S.B., \& Enjain, B.M. (in press). Only the lonely: The curious case of exclusion and rejection. In K. Williams \& S. Nida (Eds.), Frontiers handbook of ostracism, social exclusion, and rejection. New York, NY: Psychology Press.

\section{PRESENTATIONS}

*Italics indicate undergraduate student authors that I mentored

Bell, S.B., Madison Yee *, \& DeWall, C.N. (2017) “The effects of depletion and brain stimulation on motivation." Oral presentation at the TriState Conference on Animal Learning and Behavior.

Bell, S.B. \& DeWall, C.N. (2017) "Pressing the dopamine button: The effects of brain stimulation and impulsivity on reward sensitivity." Poster presentation at the Social Psychology and Personality international conference.

Bell, S.B., Paule, M.G., \& Chelonis, J.J. (2014) "Effects of Motivation on Performance on a Memory Task in Children." Poster presentation at the Southwestern Psychological Association.

Bell, S.B., Irons, G.L., Paule, M.G., \& Chelonis, J.J. (2014) "Relationship Between Performance on a Progressive Ratio Task and a Delayed Matching-to-Sample Task." Poster presentation at the International Association for Behavior Analysis.

Bell, S.B., Baldwin., S.L., Paule, M.G., \& Chelonis, J.J. (2014) "Influence of Age and IQ on Visual Discrimination Ability in Children." Poster presentation at the Southwestern Psychological Association. 
Bell, S.B., Baldwin., S.L., Bussard, S.M., Paule, M.G., \& Chelonis, J.J. (2014) "Effect of IQ on a Condition Position Response Task in Children.” Poster presentation at the International Association for Behavior Analysis.

\section{MEMBERSHIPS}

Society for Personality and Social Psychology

Association of Applied Behavior Analysis

Southwestern Psychological Association

Psi Chi

Ohio Psychological Association

Northeastern Psychology Association 